Article

\title{
A New Adsorbent Composite Material Based on Metal Fiber Technology and Its Application in Adsorption Heat Exchangers
}

\section{Ursula Wittstadt ${ }^{1, *}$, Gerrit Füldner ${ }^{1, \dagger}$, Olaf Andersen ${ }^{2, \dagger}$, Ralph Herrmann ${ }^{3, \dagger}$ and Ferdinand Schmidt ${ }^{4}$}

1 Fraunhofer Institute for Solar Energy Systems ISE, Heidenhofstr. 2, D-79110 Freiburg, Germany; E-Mail: gerrit.fueldner@ise.fraunhofer.de

2 Fraunhofer Institute for Manufacturing and Advanced Materials IFAM, Branch Lab Dresden, Winterbergstraße 28, D-01277 Dresden, Germany; E-Mail: olaf.andersen@ifam-dd.fraunhofer.de

3 SorTech AG, Zscherbener Landstr. 17, D-06126 Halle/Saale, Germany;

E-Mail: ralph.herrmann@sortech.de

4 Karlsruhe Institute of Technology (KIT), Institute of Fluid Machinery (FSM), Kaiserstr. 12, 76131 Karlsruhe, Germany; E-Mail: ferdinand.schmidt@kit.edu

$\dagger$ These authors contributed equally to this work.

* Author to whom correspondence should be addressed; E-Mail: ursula.wittstadt@ise.fraunhofer.de; Tel./Fax: +49-761-4588-5408.

Academic Editor: Chi-Ming Lai

Received: 10 June 2015 / Accepted: 30 July 2015 / Published: 10 August 2015

\begin{abstract}
In order to achieve process intensification for adsorption chillers and heat pumps, a new composite material was developed based on sintered aluminum fibers from a melt-extraction process and a dense layer of silico-aluminophosphate (SAPO-34) on the fiber surfaces. The SAPO-34 layer was obtained through a partial support transformation (PST) process. Preparation of a composite sample is described and its characteristic pore size distribution and heat conductivity are presented. Water adsorption data obtained under conditions of a large pressure jump are given. In the next step, preparation of the composite was scaled up to larger samples which were fixed on a small adsorption heat exchanger. Adsorption measurements on this heat exchanger element that confirm the achieved process intensification are presented. The specific cooling power for the adsorption step per volume of composite is found to exceed $500 \mathrm{~kW} / \mathrm{m}^{3}$ under specified conditions.
\end{abstract}


Keywords: adsorption heat exchanger (AdHEX); adsorption kinetics; SAPO-34; partial support transformation (PST); metal fibers; melt-extraction process

\section{Introduction}

In the development of adsorption heat pumps and chillers over the past decades, it has been a persistent goal to increase the volume-specific cooling or heating power to achieve more compact and light-weight units. The design of improved adsorption heat exchangers continues to take a central place in this effort.

Perhaps the simplest concept of an adsorption heat exchanger is a bed of adsorbent grains in a volume, part of which is occupied by some kind of heat exchanger. This configuration is widely used, and it can simply be obtained by pouring adsorbent grains into the volume in which the heat exchanger has been placed, and possibly densifying the bed by vibration. Whereas in standard applications of adsorbent beds (such as gas separation) the focus is on selectivity, for heat pumps and chillers the focus is on the heat of adsorption and the intensity of the heat transfer processes (during exothermal adsorption and endothermal desorption).

Therefore, the enhancement of heat conductivity within the adsorbent layer or bed is discussed by many authors (see e.g., references in [1]). The best heat transfer achievable as the limiting case of an adsorbent bed is obtained for a single layer of adsorbent grains on each heat exchanger surface, which is an approach taken, for example, in some zeolite/water heat pumps that have become available on the market recently ([2-4]). As an alternative to designs with a single adsorbent bed, additives have been proposed to enhance thermal conductivity. Wang et al. [5] have shown that a composite of polyaniline and adsorbents leads to a four-fold rise in thermal conductivity of the bed, whereas the compression of the bed improves it only by a factor of 1.5. Zhang [6] enhances the heat transfer in a cylindrical double tube by inserting fins in an adsorbent bed, whereas Demir et al. [7] and Rezk, Al-Dadah, Mahmoud, and Elsayed [1] investigate the effect of metal additives. Many experimental investigations on the performance of adsorbent beds in combination with finned tubes or lamella heat exchangers have been done [8-11]. Other authors propose to use commercially available plate-fin heat exchangers [12-14]. An overview on different concepts is given by Sharafian and Bahrami [15]. Here, the mass-specific cooling power ranges from 0.02 to $0.8 \mathrm{~kW} / \mathrm{kg}$ of the adsorbent. Improvement of the thermal contact between the adsorbent and the heat exchanger, beyond the "packed bed" concept in its "single layer of grains" limit, can be achieved by increasing the contact surface through a binding agent or glue.

Coating the heat exchanger surface directly reduces the thermal contact resistance between the heat exchanger and the adsorbent. Jaeschke and Wolf [16] propose to glue a single layer of silica gel onto the surface of a finned-tube heat exchanger, whereas Freni et al. [17] report an increase by a factor of 10 to 20 in power density for a binder-based coating with the silica gel/calcium chloride composite material SWS-1L onto finned tubes compared to a granular bed. Other binder-based coatings show similar behavior $[18,19]$.

Direct crystallization allows binding the pure adsorbent directly onto the heat exchanger surface. The absence of additional material augments the mass ratio of adsorbent to non-adsorbent material [20] and often shows a high stability [21,22]. In some cases, direct crystallization leads to a much more 
compact adsorbent layer (with a density close to the single-crystal density) than is achievable through a coating process. Different materials such as aluminum [23,24], copper [25], stainless steel [26], or graphite [27] can be used as a substrate.

Thick layers result in a higher adsorbent mass and thus an increase in Coefficients of Performance (COPs), but mass transfer may become the limiting factor. Especially when using water as a working fluid, the low operating pressure restricts the thickness of compact layers, whereas other working pairs like ammonia/activated carbon with a high operating pressure show less sensitivity to this restriction [28]. To overcome this issue, the surface area of the heat exchanger has to be enlarged considerably. The use of honeycomb structures [29], foams [25,30], or fiber material [31] has been proposed. Recently, Tatlier et al. [32] investigated coatings of zeolite A on stainless steel plates with different layer thickness $(58-176 \mu \mathrm{m})$. They show that up to a certain layer thickness, the higher amount of adsorbents can compensate the reduction in rate of adsorption. Under the conditions investigated, an optimum was found for a layer thickness of 130-140 $\mu \mathrm{m}$. An overview on recent developments in the field of coated adsorption heat exchangers and their characterization can be found in [33]. In this paper, we present a novel composite material of aluminum fibers coated by a silico-alumino-phosphate (SAPO-34) with a chabasite structure using a partial support transformation (PST) method as described by Bauer, Herrmann, Mittelbach, and Schwieger [23]. SAPO-34 has been shown to be a suitable adsorbent for heat transformation of low grade heat $\left(<100{ }^{\circ} \mathrm{C}\right)$ [34-37]. Both the characteristics of the fiber material and the fiber-adsorbent composite are investigated. The application in adsorption processes is shown for small samples $(30 \mathrm{~mm} \times 30 \mathrm{~mm} \times 3.9 \mathrm{~mm})$. Finally, the feasibility of the scale-up to a new type of compact adsorption heat exchanger is presented and its water uptake behavior is examined.

\section{Preparation of Composite Material}

\subsection{Aluminum Fiber Structures}

Short fibers of the aluminum alloy AlCu5 (aluminum with $5 \mathrm{wt} \%$ copper), specially designed for the required sintering process, have been produced by crucible melt extraction (CME) [38]. Porous bodies of various external shapes can be manufactured from such fibers through a process of fiber deposition and sintering, as described in detail in [39]. The alloy AlCu5 has been chosen for reasons of sinterability and good heat conductivity. Its density was found slightly higher than that of pure copper $\left(3000 \mathrm{~kg} / \mathrm{m}^{3}\right.$ instead of $2700 \mathrm{~kg} / \mathrm{m}^{3}$ ).

As liquid phase sintering has to be applied in order to achieve a good material bonding between the individual fibers, a sufficiently large super-solidus temperature interval is necessary in order to achieve a stable process window. The microstructure of the sintered fiber samples shows finely dispersed $\mathrm{Al} 2 \mathrm{Cu}$ precipitates with a higher concentration at the grain boundaries. A patent on such super-solidus sintered aluminum alloy fiber structures made from eutectic alloys has been granted [40].

The CME process yields fibers with a low variation in length (mean lengths are determined by shape of extraction disc, typically 3 to $15 \mathrm{~mm} \pm 10 \%$ ) and mean fiber diameters ranging from 50 to $250 \mu \mathrm{m}$. The geometric standard deviation of the fiber diameter is typically in the order of 2. Sintered fiber structures show a pore size distribution around a mean value that depends in a complex way on the geometric properties of the individual fibers and on the parameters of the subsequent processing [41]. 
In general, individual pore sizes may reach from 5 to $500 \mu \mathrm{m}$, with the mean pore size ranging from 50 to $250 \mu \mathrm{m}$, depending on the chosen porosity and the fiber diameter, i.e., at the same porosity a finer diameter results in a finer mean pore size.

Similarly, the specific surface area may be adjusted by choosing a certain combination of porosity and mean fiber diameter. Attainable porosities range from $50 \%$ to $90 \%$. The volume-specific surface area of these exclusively open-porous structures thus covers values from 2500 to $50,000 \mathrm{~m}^{2} / \mathrm{m}^{3}$.

The heat conductivity of such sintered metal fiber structures depends largely on the porosity level of the structure. Due to the manufacturing process, their heat conductivity has been found to be highly anisotropic [42]. Heat conduction along the direction of preferred fiber orientation may be two-to-three times higher than along the other directions. A factor influencing the degree of anisotropy is the fiber length, with longer fibers leading to stronger anisotropy. However, quantitative data on this hypothesis is not yet available.

The higher the relative density of the structure, the higher is the heat conductivity and the provided surface area for the zeolite coating. However, the accessibility of the structure for coating and transport of water vapor will be hindered when the resulting pore sizes are too small, therefore a good compromise was found with a porosity of $70 \%$ to $80 \%$ in conjunction with a fiber diameter of 100 to $200 \mu \mathrm{m}$, i.e., for the AlCu5 fiber batch D108 with a mean equivalent diameter of $125 \mu \mathrm{m}$ and a measured volume-specific surface area of $30.000 \mathrm{~m}^{2} / \mathrm{m}^{3}$, the resulting specific surface area amounts to 6000 and $9000 \mathrm{~m}^{2} / \mathrm{m}^{3}$ for a porosity of $80 \%$ and $70 \%$, respectively. The measurement of the specific surface area is based on metallographic cross sections of a larger number of single fibers (typically $>500$ ). Computed tomography has shown that the specific surface values after sintering are very close to the metallographically measured values, meaning that the loss of surface due to sintering is typically in the range of 5\% to $10 \%$. Effective heat conductivities in this porosity range lie between 5 and $25 \mathrm{~W} /(\mathrm{m} \mathrm{K})$, depending on the actual porosity of the sample and the direction of the heat flux in relation to the fiber orientation.

\subsection{In Situ Crystallization of SAPO-34 on Aluminum Fiber Structures}

In situ crystallization of SAPO-34 on aluminum supports has been reported by Bauer, Herrmann, Mittelbach, and Schwieger [23] and in US 8,053,032 B2 [24]. This process can also be described as a consumptive crystallization, since the Al support is partially transformed into the micro-porous adsorbent material SAPO-34. During the first part of this formation of a zeolitic aluminum phosphate, the metallic aluminum is dissolved to be available as the required Al source. Since the dissolution is controlled by the reaction conditions, it is possible to adjust the loss of fiber thickness to an amount that keeps the fibers itself and the fiber-fiber sinter connections intact. The solder for soldering the fiber package onto the heat exchanger was chosen to withstand the dissolution. On the other hand, the controlled crystal growth on the surface locally protects the $\mathrm{Al}$, which leads to an advantageous micro-structured Al-adsorbent interface with an enhanced area for heat transport. This property also results in a very good mechanical bond between metal and adsorbent, which is especially important in sorption applications with cyclic temperature changes.

The SAPO-34 loading was adjusted to cover the fiber package with a mean thickness of approximately $45 \mu \mathrm{m}$. This amount of adsorbent keeps the porosity through the composite for water vapor transport while a high mass of adsorbent is realized (mean macropore diameter: $150 \mu \mathrm{m}$; see Table 1). 
Table 1. Material properties of composite material.

\begin{tabular}{ccc}
\hline Material propery & Unit & Value \\
\hline Heat Conductivity & $\mathrm{W} / \mathrm{m} \mathrm{K}$ & 9 \\
Mean macropore diameter & $\mathrm{m}$ & $150 \times 10^{-6}$ \\
Macro porosity fibers & $\%$ & 75 \\
Macro porosity composite & $\%$ & 29 \\
Tortuosity & - & $2-3$ \\
Permeability & $\mathrm{m}^{2}$ & $1 \times 10^{-10}$ \\
\hline
\end{tabular}

The structure of the zeolite coating was confirmed to be CHA by the XRD pattern (X'Pert Pro MPD, see Figure 1). The mass of the formed adsorbent was determined by measuring the mass loss during calcination at $520^{\circ} \mathrm{C}$ and comparison with powder data (SAPO-34 powder: $18.7 \%$ calcination mass loss) as well as by water adsorption on the basis of the SAPO-34 isotherm (see Equation (2)). ICP-OES (Perkin Elmer Plasma 400) measurements of zeolite removed from the support show a composition of ( $\left.\mathrm{Si}_{0.06} \mathrm{Al}_{0.49} \mathrm{P}_{0.45}\right) \mathrm{O}_{2}$. The density of the adsorbent layer amounts to around $1500 \mathrm{~kg} / \mathrm{m}^{3}$. This value was calculated from the adsorbent mass and the layer thickness (measured by cross section SEM, Hitachi S 2400).

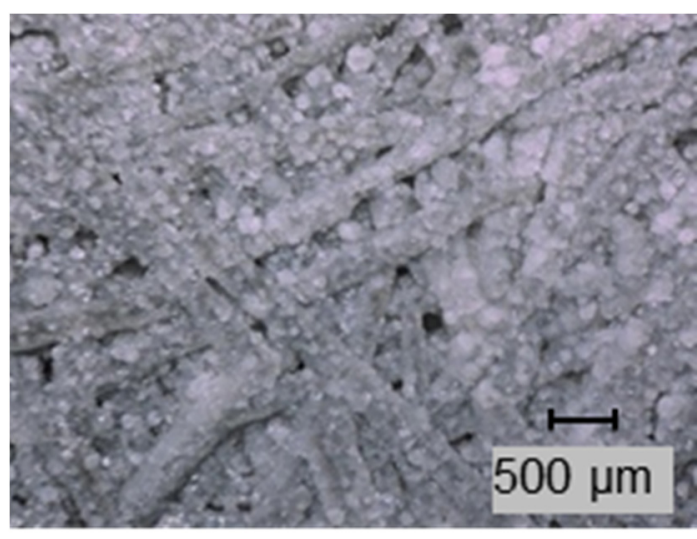

(a)

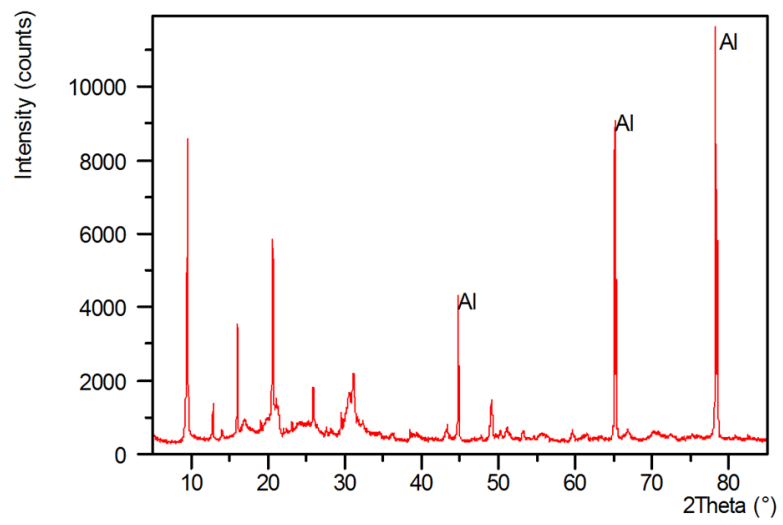

(b)

Figure 1. (a) Microscopic view of a fiber-SAPO-34 sample; (b) XRD pattern of the SAPO-34 coated fiber sample; the reflexes of the fiber support are marked with Al.

\subsection{Material Properties}

The most important properties of the composite material and its application for adsorption heat exchangers (AdHEX) have been determined (see Table 1).

The thermal diffusivity of the composite material across the fiber structure has been determined with a flash method in a LFA 447 NanoFlash by Netzsch. With a specific heat capacity of $900 \mathrm{~J} /(\mathrm{kg} \mathrm{K})$ [43] and a composite density of $1510 \mathrm{~kg} / \mathrm{m}^{3}$, the heat conductivity is found to be $9 \pm 1 \mathrm{~W} /(\mathrm{m} \mathrm{K})$ [44]. This is more than an order of magnitude higher than the heat conductivity of the adsorbent material and thus leads to a better heat transfer characteristic.

The pore size distribution of both the uncoated fibers as well as the composite material has been determined by mercury porosity under a protective gas atmosphere to prevent the formation of amalgam. 
A maximum of the pore size distribution is found at a pore width of around $330 \mu \mathrm{m}$ for the pure aluminum fiber matrix and $150 \mu \mathrm{m}$ for the macropores of the composite structure.

As viscous flow is the main transport mechanism (Knudsen number $<<1$ ) in the macropores of the composite material, the permeability $\kappa$ can be determined by:

$$
\kappa=\psi \cdot \frac{d_{\text {pore }}^{2}}{32 \cdot \mu}
$$

with $\Psi$ being the macro-porosity of the composite, $\mu$ the tortuosity, and $d_{\text {pore }}$ the diameter of the macropores. By measurements in the slip flow regime (transition between Knudsen diffusion and viscous flow [45]), a tortuosity $\mu$ of 2 to 3 has been determined [44]. Thus, a value in the order of $1 \times 10^{-10} \mathrm{~m}^{2}$ can be calculated for the permeability.

\section{Adsorption Characteristics of Small Sample}

The adsorption behavior of the small sample of the composite material (see Figure 2) has been investigated by a Large Pressure Jump (LPJ) method in a set-up described by Schnabel, Tatlier, Schmidt, and Erdem-Şenatalar [25]. The sample is placed on a cold plate in a vacuum chamber: thermostats control the temperature of the cold plate and the sample is desorbed (here: at $95{ }^{\circ} \mathrm{C}$ ), either against a vacuum pump or against a temperature-controlled water flask, setting a certain condenser pressure for the desorption process and thus enabling the preparation of the sample at a well-defined initial adsorbate loading. The pressure in the vapor chamber is the saturation pressure of the water flask (here: $10^{\circ} \mathrm{C}$, i.e., 12 mbar). The sample is cooled down to an adsorption temperature of $38.7^{\circ} \mathrm{C}$ and adsorption is started by opening the valve between the vapor chamber and the measurement cell. The decrease in pressure in the combined volume over time is detected by a pressure sensor and the amount of water adsorbed by the sample can thus be determined with an accuracy of $\pm 5 \%$ under the assumption that water vapor is an ideal gas [46] (see Figures 3 and 4).

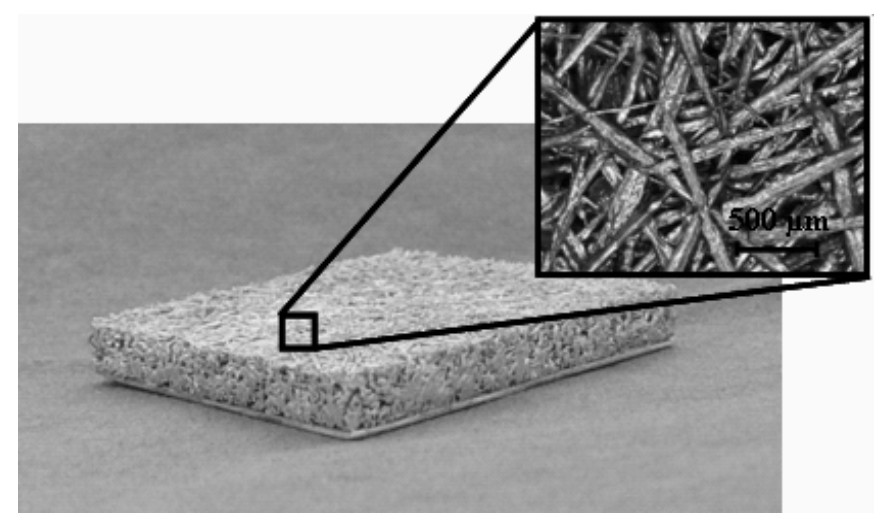

Figure 2. Sample of fiber-SAPO-34 composite material $(0.03 \mathrm{~m} \times 0.03 \mathrm{~m} \times 0.0039 \mathrm{~m})$, carrier: Al sheet of $0.4 \mathrm{~mm}$ thickness. 


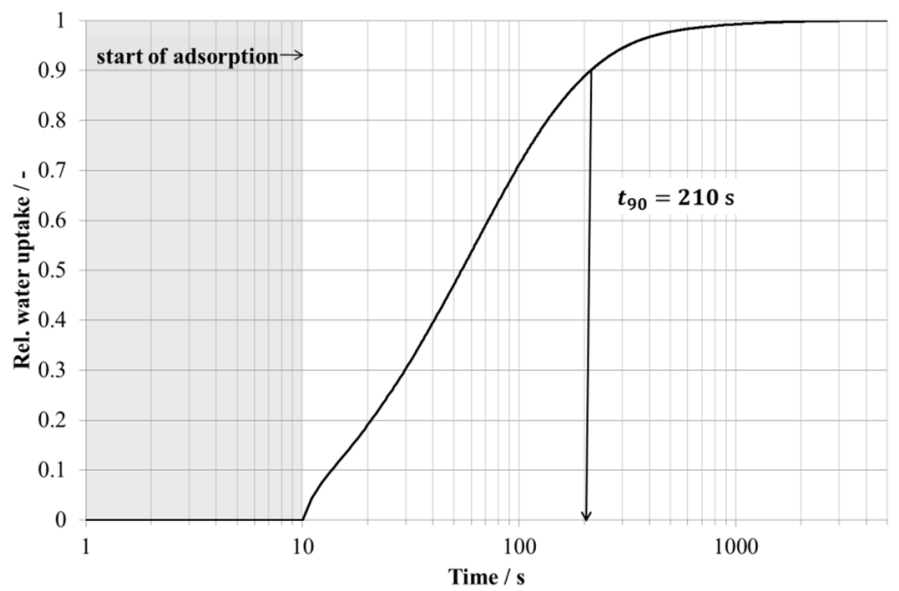

Figure 3. Water uptake (relative to final uptake) over time at $38.7^{\circ} \mathrm{C}$ for small sample at a start loading of $0.06 \mathrm{~g}$ H2O/gAde.

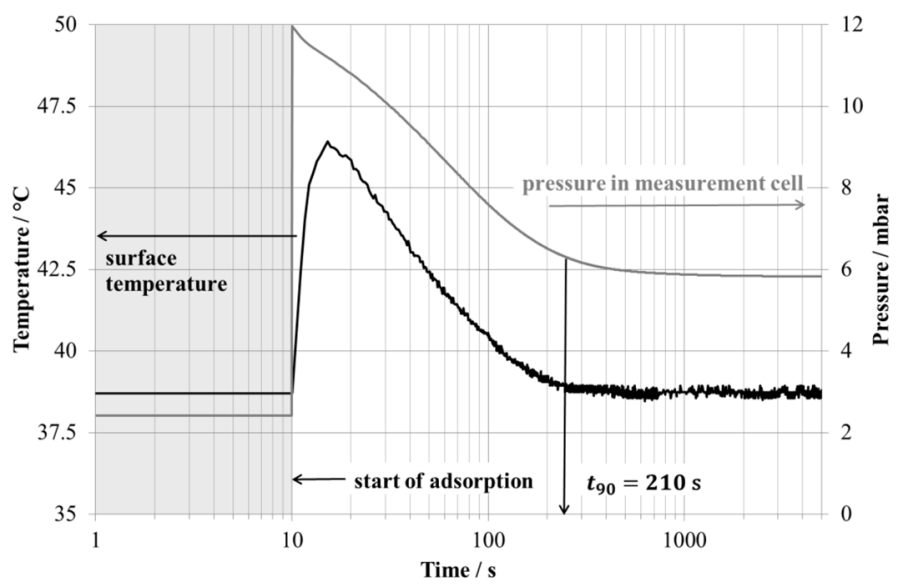

Figure 4. Surface temperature of sample and vapor pressure in measurement cell during water uptake as shown in Figure 3.

Figure 3 shows the water uptake over time measured at $38.7^{\circ} \mathrm{C}$. Further results are given in Table 2 .

Table 2. Main parameters of small sample and prototype.

\begin{tabular}{clcc}
\hline Parameter & Unit & Small Sample & Prototype \\
\hline Volume & & & \\
\hline Total & $\mathrm{m}^{3}$ & $0.0039 \times 10^{-3}$ & $3 \times 10^{-3} \mathrm{a}$ \\
Profiles/support & $\mathrm{m}^{3}$ & $0.0004 \times 10^{-3}$ & $0.495 \times 10^{-3}$ \\
Fiber & $\mathrm{m}^{3}$ & $0.0035 \times 10^{-3}$ & $0.315 \times 10^{-3}$ \\
\hline Mass & & & \\
\hline Mass adsorbent & $\mathrm{kg}$ & $2.2 \times 10^{-3}$ & 0.240 \\
Total mass ${ }^{\mathrm{b}}$ & $\mathrm{kg}$ & $6.8 \times 10^{-3}$ & 1.350 \\
\hline Specific values & & & \\
\hline Mass adsorbent per total mass & $\mathrm{kg} / \mathrm{kg}$ & 0.32 & 0.18 \\
Mass adsorbent per volume composite & $\mathrm{kg} / \mathrm{m}^{3}$ & 620 & 760 \\
\hline
\end{tabular}

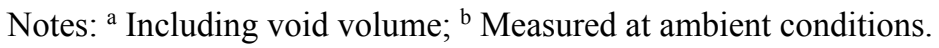


The sample adsorbs $180 \mathrm{mg}$ of water in a short time: the time to reach $90 \%$ of the final uptake $\left(t_{90}\right)$ is $210 \mathrm{~s}$, which leads to a volume-specific cooling power density of over $500 \mathrm{~kW} / \mathrm{m}^{3}$ of the composite material.

\section{Lab-Scale Adsorbent Heat Exchanger (AdHEX)}

The application of the newly developed composite material is demonstrated in a lab-scale adsorption heat exchanger.

\subsection{Construction and Coating}

A first scale-up to a heat exchanger device has been realized. The design is based on aluminum extrusion profiles which are welded into a collector tube. The fibers are sintered before being applied onto the heat exchanger. In the second step, fiber stripes are soldered onto the extrusion profiles. The whole fiber heat exchanger is then coated with SAPO-34 by a partial support transformation technique as described in Section 2.2.

The adsorption heat exchanger (AdHEX) is depicted in Figure 5. Its main parameters are given in Table 2.

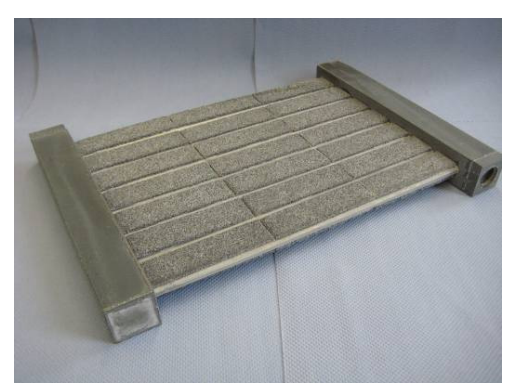

(a)

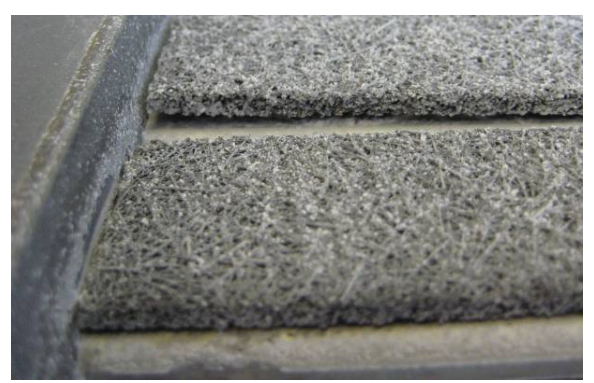

(b)

Figure 5. (a) Adsorption heat exchanger (AdHEX); (b) Detailed view: some parts of the fiber composite material still show poor contact to the surface of the heat exchanger.

\subsection{Characterization}

The kinetics of adsorption have then been measured in the set-up depicted in Figure 6. Its core part is a vacuum chamber in which the adsorption heat exchanger is placed. The water uptake is measured using a scale (WZA 8200, Sartorius, $8200 \mathrm{~g} \pm 0.01 \mathrm{~g}$ ) while the adsorption heat exchanger is connected to the hydraulic loop of the system. An evaporator is placed below the chamber and provides the water vapor to be adsorbed. During desorption, the same device is used as a condenser. Both the evaporator/condenser unit and AdHEX are equipped with volume flow and temperature sensors to determine the energy balance. The influence of different process parameters on the measurement of water uptake, such as temperature, pressure, and volume flow, has been investigated by Wittstadt et al. [47]. A maximum error of $\pm 2 \mathrm{~g}$ in the measurement of water uptake has been determined.

Other than the measurement on small samples (see Section 3), adsorption takes place under quasi-isobaric conditions. After complete desorption, the connection between the evaporator/condenser and AdHEX is closed and both devices are cooled down to adsorption conditions. Due to the water 
vapor, which remains in the free volume of the vacuum chamber, this step is not isosteric. Since the pressure inside the chamber is measured, the water loading of the sorbent material can be calculated using the equilibrium data of SAPO-34. The following standardized Dubinin approach [48] is used for their description.

$$
W(A)=\frac{a+c \cdot A+e \cdot A^{2}+g \cdot A^{3}+i \cdot A^{4}+k \cdot A^{5}}{1+b \cdot A+d \cdot A^{2}+f \cdot A^{3}+h \cdot A^{4}+j \cdot A^{5}}
$$

with $W$ being the adsorbed volume in $\mathrm{cm}^{3} / \mathrm{g}$ adsorbent and $A$ the adsorption potential in $\mathrm{J} / \mathrm{g}$ adsorbent. The parameters $\mathrm{a}-\mathrm{k}$ can be found in Table 3 .

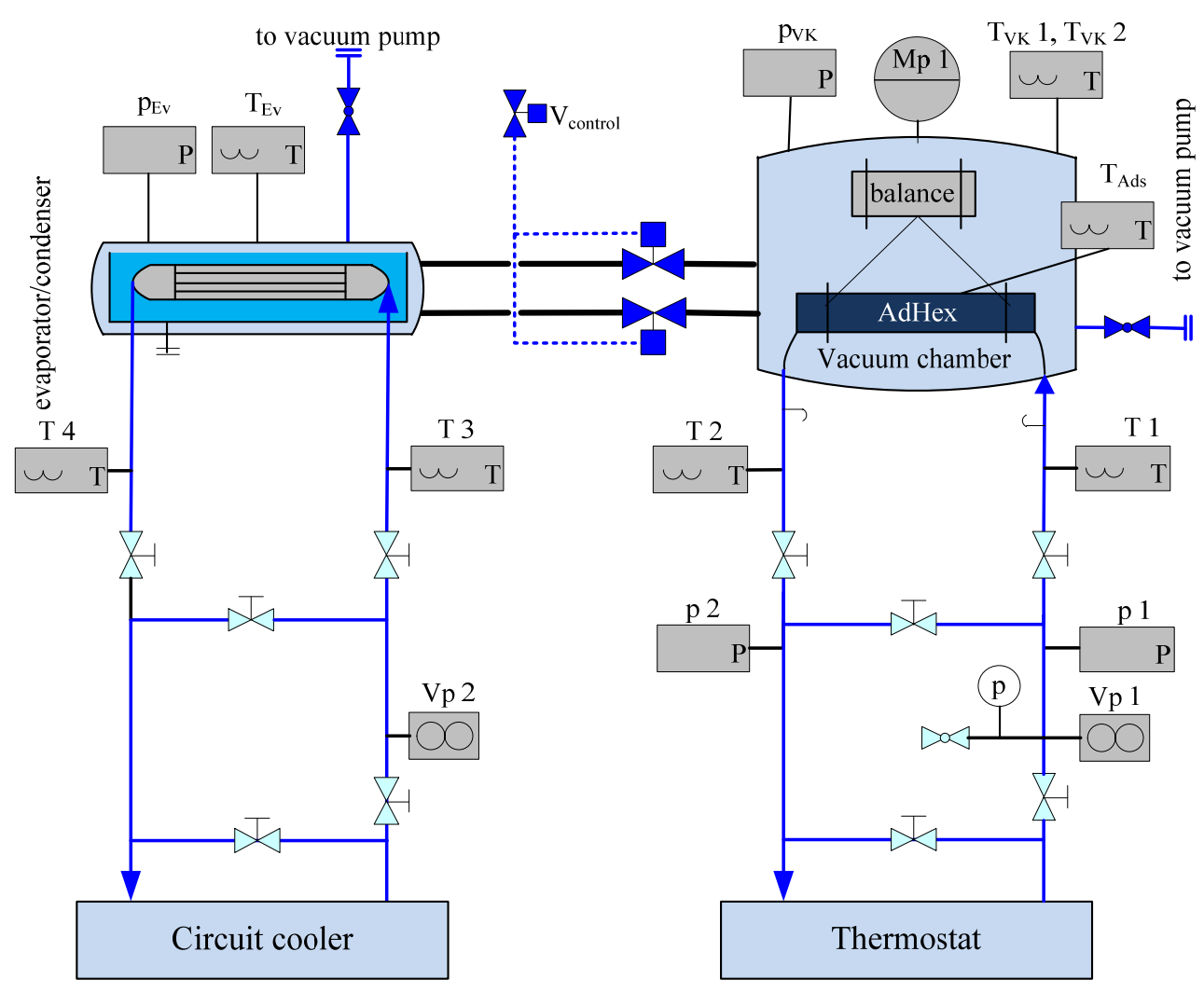

Figure 6. Schematic of the set-up for the characterization of small AdHEX.

Table 3. Parameters for the standardized Dubinin characteristic curve.

\begin{tabular}{cc|cc}
\hline Parameter & Value & Parameter & Value \\
\hline $\mathrm{a}$ & $0.33657 \mathrm{~cm}^{3} / \mathrm{g}$ & $\mathrm{g}$ & $-1.26124 \times 10^{-8}\left(\mathrm{~cm}^{3} \cdot \mathrm{g}^{2}\right) / \mathrm{J}^{3}$ \\
$\mathrm{~b}$ & $-0.00786 \mathrm{~g} / \mathrm{J}$ & $\mathrm{h}$ & $3.86925 \times 10^{-11} \mathrm{~g}^{4} / \mathrm{J}^{4}$ \\
$\mathrm{c}$ & $-0.00270 \mathrm{~cm} / \mathrm{J}$ & $\mathrm{i}$ & $9.22605 \times 10^{-12}\left(\mathrm{~cm}^{3} \cdot \mathrm{g}^{3}\right) / \mathrm{J}^{4}$ \\
$\mathrm{~d}$ & $2.53508 \times 10^{-5} \mathrm{~g}^{2} / \mathrm{J}^{2}$ & $\mathrm{j}$ & $-8.10788 \times 10^{-15} \mathrm{~g}^{5} / \mathrm{J}^{5}$ \\
$\mathrm{e}$ & $8.39344 \times 10^{-6}\left(\mathrm{~cm}^{3} \cdot \mathrm{g}\right) / \mathrm{J}^{2}$ & $\mathrm{k}$ & $-2.48858 \times 10^{-15}\left(\mathrm{~cm}^{3} \cdot \mathrm{g}^{4}\right) / \mathrm{J}^{5}$ \\
$\mathrm{f}$ & $-4.35518 \times 10^{-8} \mathrm{~g}^{3} / \mathrm{J}^{3}$ & & \\
\hline
\end{tabular}

A comparison of the water uptake behavior is given in Figure 7. The removal of the heat of adsorption influences the speed of the water uptake. With a very low volume flow of the heat transfer fluid $(0.2 \mathrm{~L} / \mathrm{min}$, i.e., residual time of $100 \mathrm{~s})$ the $90 \%$ uptake time is $1520 \mathrm{~s}$, around ten times higher than for the small sample. With a residence time of only $10 \mathrm{~s}(2 \mathrm{~L} / \mathrm{min})$ this time can be reduced to $630 \mathrm{~s}$. 
A further intensification of the heat transfer to the fluid is not possible with the given heat exchanger geometry at a reasonable volume flow or pressure drop, respectively. As the flow channels have a small hydraulic diameter of around $3 \mathrm{~mm}$, the flow stays laminar $(\mathrm{Re}=12$ and 121 , respectively).

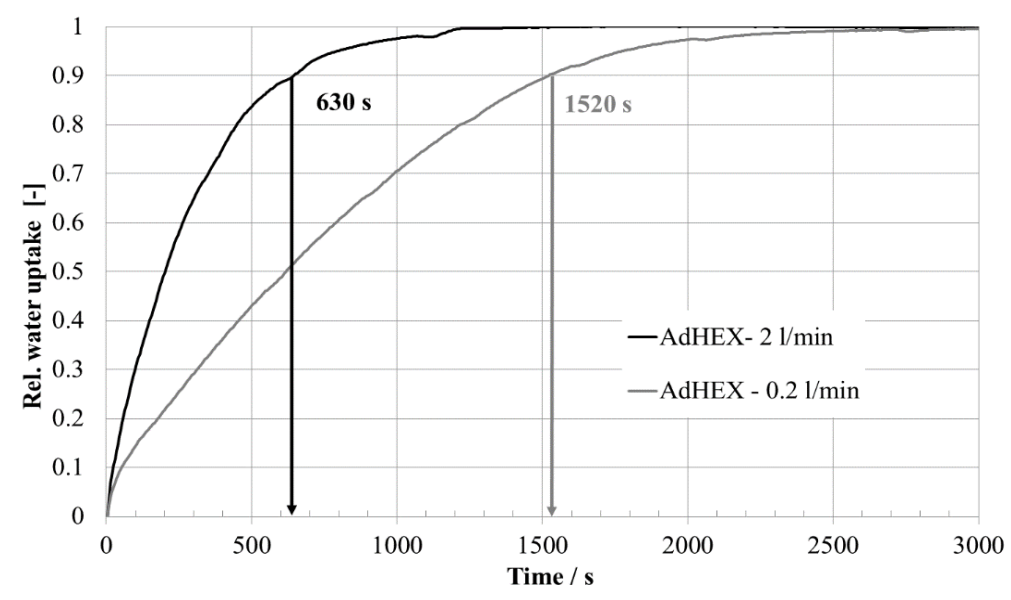

Figure 7. Comparison of water uptake behavior of the composite material in an AdHEX. The influence of the heat removal during adsorption in the AdHEX is shown for different volume flows of the heat transfer fluid.

The absolute water uptake at the end of adsorption differs within the expected error range. The main influencing parameters are uncertainties in the mass of active adsorbent and the correlation of the equilibrium data.

A direct comparison of the uptake behavior of the AdHEX to the one of the small sample is not possible as the measurements have been carried out under non-isobaric conditions and, hence, the uptake per $g$ of adsorbent differs: the small sample adsorbs only around $40 \%$ of the water that is adsorbed per $g$ of adsorbent in the AdHEX (0.11 g/g and $0.22 \mathrm{~g} / \mathrm{g}$, respectively), since the end pressure arrives at 5.8 mbar for the small sample, whereas for the AdHEX measurements, the end pressure lies at 11.9 mbar. Figure 8 shows the start and end loadings for the measurements on the $39{ }^{\circ} \mathrm{C}$ isotherm calculated from the equilibrium data of SAPO-34 (characteristic curve, see Equation (2)).

The relative water uptake behavior of the small sample can be used as a best-case scenario. Less heat has to be removed and the heat removal is close to ideal.

Although the uptake behavior is considerable slower for the AdHEX with $t_{90}$ being three to seven times higher depending on the heat removal (see Figure 7), the volume-specific cooling power (VSCP) is slightly higher (see Figure 9). This is due to the fact that the composite material contains a higher amount of adsorbent material per volume. This outweighs the slower kinetics whereas the utilization of the sorbent material is lower in the AdHEX: the mass-specific cooling power (MSCP) is $0.77 \mathrm{~kW} / \mathrm{kg}$, which is $20 \%$ lower than the MSCP of the small sample $(0.96 \mathrm{~kW} / \mathrm{kg})$. The rise-up time and sorption speed lie within the order of magnitude as reported in [19]. A direct comparison is difficult operation conditions as well as measurement procedure differences. 


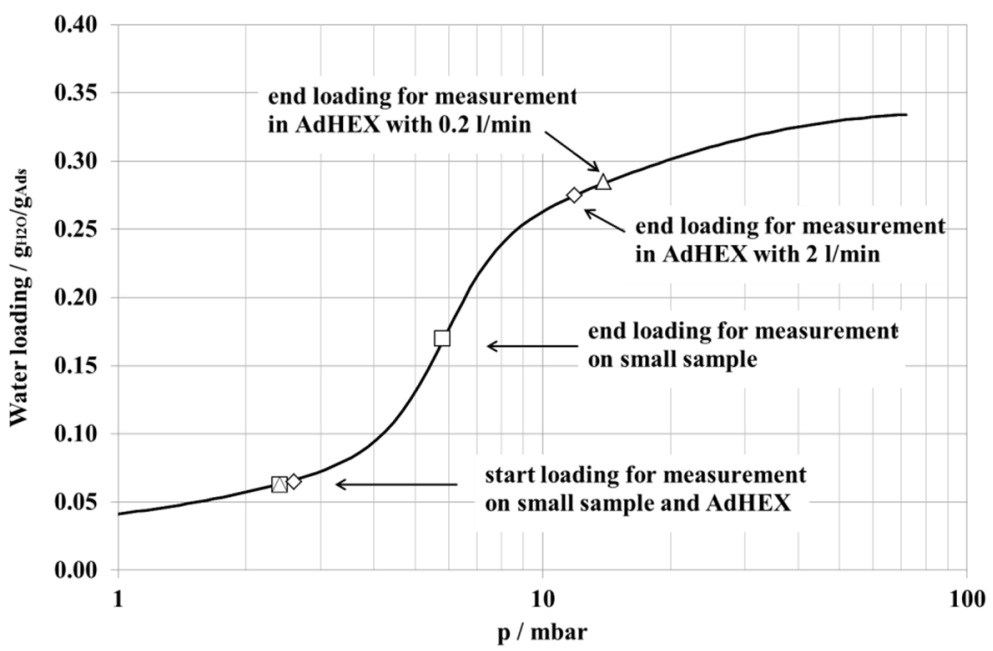

Figure 8. Isotherm at $39{ }^{\circ} \mathrm{C}$ for SAPO-34, calculated from the characteristic curve (Equation (2)). Open symbols indicate the start and end loading of all measurements. End loading of AdHEX differs slightly due to deviation in operation conditions (see Table 4).

Table 4. Parameters of the experimental characterization and main results of the water uptake behavior.

\begin{tabular}{cccc}
\hline Parameter & Small Sample & \multicolumn{2}{c}{ AdHEX } \\
\hline Volume flow of heat transfer fluid & & $0.2 \mathrm{~L} / \mathrm{min}$ & $2 \mathrm{~L} / \mathrm{min}$ \\
Desorption temperature & $95{ }^{\circ} \mathrm{C}$ & $92{ }^{\circ} \mathrm{C}$ & $95{ }^{\circ} \mathrm{C}$ \\
Adsorption temperature & $38.7{ }^{\circ} \mathrm{C}$ & $39.2{ }^{\circ} \mathrm{C}$ & $39.8^{\circ} \mathrm{C}$ \\
Starting pressure & $2.4 \mathrm{mbar}$ & $2.4 \mathrm{mbar}$ & $2.6 \mathrm{mbar}$ \\
End pressure & $5.8 \mathrm{mbar}$ & $11.9 \mathrm{mbar}$ & $11.9 \mathrm{mbar}$ \\
Pressure Jump & $2.4-12.0 \mathrm{mbar}$ & $2.4-12.1 \mathrm{mbar}$ & $2.6-11.9 \mathrm{mbar}$ \\
Condenser temperature/pressure & $30{ }^{\circ} \mathrm{C} / 42 \mathrm{mbar}$ & $24{ }^{\circ} \mathrm{C} / 30 \mathrm{mbar}$ & $21{ }^{\circ} \mathrm{C} / 25 \mathrm{mbar}$ \\
Start loading (calculated) & $0.06 \mathrm{~g} / \mathrm{g}$ & $0.06 \mathrm{~g} / \mathrm{g}$ & $0.06 \mathrm{~g} / \mathrm{g}$ \\
End loading (calculated) & $0.17 \mathrm{~g} / \mathrm{g}$ & $0.28 \mathrm{~g} / \mathrm{g}$ & $0.27 \mathrm{~g} / \mathrm{g}$ \\
Rel. water uptake (calculated) & $0.11 \mathrm{~g} / \mathrm{g}$ & $0.22 \mathrm{~g} / \mathrm{g}$ & $0.21 \mathrm{~g} / \mathrm{g}$ \\
Abs. water uptake (calculated) & $0.22 \mathrm{~g}$ & $52.3 \mathrm{~g}$ & $51.1 \mathrm{~g}$ \\
Rel. water uptake (measured) & $0.09 \mathrm{~g} / \mathrm{g}$ & $0.23 \mathrm{~g} / \mathrm{g}$ & $0.22 \mathrm{~g} / \mathrm{g}$ \\
Abs. water uptake (measured) & $0.18 \mathrm{~g} \pm 0.01 \mathrm{~g}$ & $55 \mathrm{~g} \pm 2 \mathrm{~g}$ & $53 \mathrm{~g} \pm 2 \mathrm{~g}$ \\
Time $90 \%$ uptake $t_{90}$ & $210 \mathrm{~s}$ & $1520 \mathrm{~s}$ & $630 \mathrm{~s}$ \\
Rise-up time $t_{80} t_{15}$ & $118 \mathrm{~s}$ & $1114 \mathrm{~s}$ & $407 \mathrm{~s}$ \\
Sorption speed $V_{\mathrm{s}}$ & $920 \times 10^{-6} 1 / \mathrm{s}$ & $187 \times 10^{-6} 1 / \mathrm{s}$ & $547 \times 10^{-6} 1 / \mathrm{s}$ \\
Water uptake at $t_{90}$ & $0.16 \mathrm{~g}$ & $49.9 \mathrm{~g}$ & $47.4 \mathrm{~g}$ \\
Cooling power $\left(t_{90}\right)$ & $2 \mathrm{~W}$ & $80 \mathrm{~W}$ & $184 \mathrm{~W}$ \\
\hline per mass adsorbent & & & \\
\hline per volume composite & $545 \mathrm{~kW} / \mathrm{m}^{3}$ & $255 \mathrm{~kW} / \mathrm{m}^{3}$ & $585 \mathrm{~kW} / \mathrm{m}^{3}$ \\
per total volume AdHEX & $273 \mathrm{~kW} / \mathrm{m}^{3}(1)$ & $98 \mathrm{~kW} / \mathrm{m}^{3}$ & $226 \mathrm{~kW} / \mathrm{m}^{3}$ \\
\hline Mass-specific cooling power $(\mathrm{MSCP})$ & $55 \mathrm{~kW} / \mathrm{m}^{3}(2)$ & $26 \mathrm{~kW} / \mathrm{m}^{3}$ & $59 \mathrm{~kW} / \mathrm{m}^{3}$ \\
\hline Volume-specific cooling power $(\mathrm{VSCP})$ & & \\
\hline
\end{tabular}

${ }^{(1)}$ : Fiber on profile as used for $\operatorname{AdHEX}^{(2)}$ : As ${ }^{(1)}$, but plus same percentage of void volume as in AdHex. 


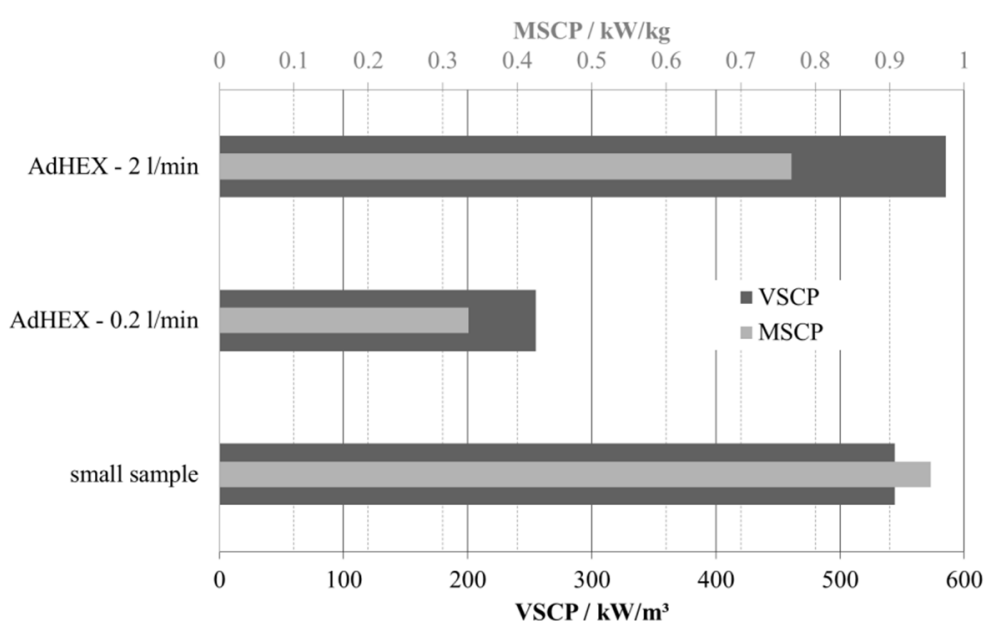

Figure 9. Mass-specific (MSCP) and volume-specific (VSCP) cooling power for the adsorption half-cycle calculated with $90 \%$ loading time of the composite material as a small sample and in an AdHEX.

In the AdHEX, the contact between the composite material and the heat exchanger surface for this first prototype is poor in some regions (see Figure 5b). A reduction of the thermal contact resistance might lead to a better performance if the mass transport into the adsorbent layer is not limiting the process. This question cannot be answered by just evaluating the experimental data, but has to be analyzed in a simulation with a detailed model of heat and mass transfer.

\section{Conclusions}

A new composite material made from AlCu5 fibers which are coated with SAPO-34 by an in situ crystallization process has been developed. The high surface area of the fiber structures allows a high amount of adsorbent per volume (up to $760 \mathrm{~kg} / \mathrm{m}^{3}$ ) with a low adsorbent layer thickness. In combination with lowering the heat transfer resistance by soldering the fiber structure onto the support, a good heat transport characteristics i realized. A VSCP of $545 \mathrm{~kW}$ per $\mathrm{m}^{3}$ of composite material measured on a small sample makes it favorable for adsorption chillers or heat pumps.

A scale-up from small samples to an AdHEX has been realized with an even higher amount of adsorbent mass and cooling power per volume of the composite. Further optimization is expected by enhancing the contact to the heat exchanger surface and by optimizing the heat transfer on the fluid side. Still, the vapor transport should be taken into account for the development of a more compact AdHEX design.

\section{Acknowledgments}

Most of this work was carried out with funding of the Fraunhofer internal project "WISA Thoka" (Thermally driven high power density cooling processes). Funding for summarizing the contents and working out this paper from the German Federal Ministry of Education and Research (BMBF) in the framework of the project WasserMod (FKZ 03SF0469) is kindly acknowledged. 


\title{
Author Contributions
}

Olaf Andersen was responsible for the design, production, and characterization of the aluminum fiber structure. Ralph Hermann realized the direct crystallization of SAPO-34 on the fiber structure. Gerrit Füldner carried out the measurements of adsorption kinetics on the small samples. Ferdinand P. Schmidt led the project "WISA Thoka" and contributed to writing the paper. Ursula Wittstadt designed the Adsorption Heat Exchanger, carried out the experiments on it, and is the main author of the paper.

\section{Conflicts of Interest}

The authors declare no conflict of interest.

\section{Nomenclature}

$\begin{array}{lll}A & \mathrm{~J} / \mathrm{g} & \text { Adsorption potential } \\ \mathrm{Re} & - & \text { Reynolds number } \\ t_{50} & \mathrm{~S} & \text { Time to reach } 50 \% \text { of final loading } \\ t_{80}-t_{15} & \mathrm{~S} & \text { Rise-up time (time span between } 15 \% \text { and } 80 \% \text { of final loading) } \\ t_{90} & \mathrm{~S} & \text { Time to reach } 90 \% \text { of final loading } \\ V_{\mathrm{s}} & 1 / \mathrm{s} & \left.\text { Sorption speed (loading }\left(t_{50}\right) / t_{50}\right) \\ W & \mathrm{~cm}^{3} / \mathrm{g} & \text { Adsorbed volume } \\ \kappa & \mathrm{m}^{2} & \text { Permeability } \\ \mu & - & \text { Tortuosity } \\ \psi & \% & \text { Macro porosity of composite material }\end{array}$

\author{
Abbreviations \\ AdHEX Adsorption heat exchanger \\ COP Coefficient of performance \\ ICP-OES Inductively Coupled Plasma-Optical Emission Spectroscopy \\ PST Partial support transformation \\ MSCP Mass-specific cooling power \\ SEM Scanning electron microscopy \\ VSCP Volume specific cooling power \\ XRD X-ray diffraction
}

\section{References}

1. Rezk, A.; Al-Dadah, R.K.; Mahmoud, S.; Elsayed, A. Effects of contact resistance and metal additives in finned-tube adsorbent beds on the performance of silica gel/water adsorption chiller. Appl. Therm. Eng. 2013, 53, 278-284. 
2. Wienen, J.; Neubert, M.; Lang, R.; Tiemeier, H. Results from field trial with gas heat pump Zeotherm by Vaillant. In Thermally Driven Heat Pumps for Heating and Cooling; Kühn, A., Ed; Universitätsverlag der TU Berlin: Berlin, Geramny, 2013.

3. Núñez, T.; Mittelbach, W.; Henning, H.-M. Development of an adsorption chiller and heat pump for domestic heating and air-conditioning applications. Appl. Therm. Eng. 2007, 27, 2205-2212.

4. Schicktanz, M.; Núñez, T. Modelling of an adsorption chiller for dynamic system simulation. Int. J. Refrig. 2009, 32, 588-595.

5. Wang, L.; Zhu, D.; Tan, Y. Heat transfer enhancement of the adsorber of an adsorption heat pump. Adsorption 1999, 5, 279-286.

6. Zhang, L.Z. Design and testing of an automobile waste heat adsorption cooling system. Appl. Therm. Eng. 2000, 20, 103-114.

7. Demir, H.; Mobedi, M.; Ülkü, S. The use of metal piece additives to enhance heat transfer rate through an unconsolidated adsorbent bed. Int. J. Refrig. 2010, 33, 714-720.

8. Riffel, D.B.; Wittstadt, U.; Schmidt, F.P.; Nunez, T.; Belo, F.A.; Leite, A.P.F.; Ziegler, F. Transient modeling of an adsorber using finned-tube heat exchanger. Int. J. Heat Mass Transf. 2010, 53, 1473-1482.

9. Chang, K.S.; Chen, M.T.; Chung, T.W. Effects of the thickness and particle size of silica gel on the heat and mass transfer performance of a silica gel-coated bed for air-conditioning adsorption systems. Appl. Therm. Eng. 2005, 25, 2330-2340.

10. Chang, W.S.; Wang, C.C.; Shieh, C.C. Experimental study of a solid adsorption cooling system using flat-tube heat exchangers as adsorption bed. Appl. Therm. Eng. 2007, 27, 2195-2199.

11. Aristov, Y.I. Experimental and numerical study of adsorptive chiller dynamics: Loose grains configuration. Appl. Therm. Eng. 2013, 61, 841-847.

12. Grisel, R.J.H.; Smeding, S.F.; de Boer, R. Waste heat driven silica gel/water adsorption cooling in trigeneration. Appl. Therm. Eng. 2010, 30, 1039-1046.

13. Freni, A.; Sapienza, A.; Glaznev, I.S.; Aristov, Y.I.; Restuccia, G. Experimental testing of a lab-scale adsorption chiller using a novel selective water sorbent "silica modified by calcium nitrate". Int. J. Refrig. 2012, 35, 518-524.

14. Santamaria, S.; Sapienza, A.; Frazzica, A.; Freni, A.; Girnik, I.S.; Aristov, Y.I. Water adsorption dynamics on representative pieces of real adsorbers for adsorptive chillers. Appl. Energy 2014, 134, 11-19.

15. Sharafian, A.; Bahrami, M. Assessment of adsorber bed designs in waste-heat driven adsorption cooling systems for vehicle air conditioning and refrigeration. Renew. Sustain. Energy Rev. 2014, 30, 440-451.

16. Jaeschke, S.; Wolf, M. Schichtverbund und seine Herstellung. German Patent DE102005038044, 10 August 2008.

17. Freni, A.; Russo, F.; Vasta, S.; Tokarev, M.; Aristov, Y.I.; Restuccia, G. An advanced solid sorption chiller using SWS-1L. Appl. Therm. Eng. 2007, 27, 2200-2204.

18. Munz, G.M.; Bongs, C.; Morgenstern, A.; Lehmann, S.; Kummer, H.; Henning, H.M.; Henninger, S.K. First results of a coated heat exchanger for the use in dehumidification and cooling processes. Appl. Therm. Eng. 2013, 61, 878-883. 
19. Dawoud, B. Water vapor adsorption kinetics on small and full scale zeolite coated adsorbers: A comparison. Appl. Therm. Eng. 2013, 50, 1645-1651.

20. Tatlier, M.; Erdem-Şenatalar, A. The effects of thermal gradients in a solar adsorption heat pump utilizing the zeolite-water pair. Appl. Therm. Eng. 1999, 19, 1157-1172.

21. Bonaccorsi, L.; Calabrese, L.; Proverbio, E. Low temperature single-step synthesis of zeolite y coatings on aluminium substrates. Microporous Mesoporous Mater. 2011, 144, 40-45.

22. Freni, A.; Frazzica, A.; Dawoud, B.; Chmielewski, S.; Calabrese, L.; Bonaccorsi, L. Adsorbent coatings for heat pumping applications: Verification of hydrothermal and mechanical stabilites. Innov. Mater. Process. Energy Syst. 2010, 50, 1658-1663.

23. Bauer, J.; Herrmann, R.; Mittelbach, W.; Schwieger, W. Zeolite/aluminum composite adsorbents for application in adsorption heat pumps. Int. J. Energy Res. 2009, 33, 1233-1249.

24. Schwieger, W.; Thangaraj, S.; Scheffler, F.; Herrmann, R.; Reddy, M.; Mittelbach, W.; Bauer, J.; Schmidt, F.; Hennig, H.-M. Method for Production of a Substrate coated with a Zeolite Layer. US 8,053,032 B2, 29 October 2004.

25. Freni, A.; Bonaccorsi, L.; Proverbio, E.; Maggio, G.; Restuccia, G. Zeolite synthesised on copper foam for adsorption chillers: A mathematical model. Microporous Mesoporous Mater. 2009, 120, 402-409.

26. Schnabel, L.; Tatlier, M.; Schmidt, F.; Erdem-Şenatalar, A. Adsorption kinetics of zeolite coatings directly crystallized on metal supports for heat pump applications (adsorption kinetics of zeolite coatings). Appl. Therm. Eng. 2010, 30, 1409-1416.

27. Bonaccorsi, L.; Bruzzaniti, P.; Calabrese, L.; Freni, A.; Proverbio, E.; Restuccia, G. Synthesis of sapo-34 on graphite foams for adsorber heat exchangers. Appl. Therm. Eng. 2013, 61, 848-852.

28. Aristov, Y.I. Adsorption dynamics in adsorptive heat transformers: Review of new trends. Heat Transf. Eng. 2014, 35, 1014-1027.

29. Lang, R.; Westerfeld, T.; Gerlich, A.; Knoche, K.F. Enhancement of the heat and mass transfer in compact zeolite layers. Adsorption 1996, 2, 121-132.

30. Guilleminot, J.-J.; Choisier, A.; Chalfen, J.B.; Nicolas, S.; Reymoney, J.L. Heat transfer intensification in fixed bed adsorbers. Heat Recover. Syst. 1993, 13, 297-300.

31. Atakan, A.; Fueldner, G.; Munz, G.; Henninger, S.; Tatlier, M. Adsorption kinetics and isotherms of zeolite coatings directly crystallized on fibrous plates for heat pump applications. Appl. Therm. Eng. 2013, 58, 273-280.

32. Tatlier, M.; Munz, G.; Fueldner, G.; Henninger, S.K. Effect of zeolite a coating thickness on adsorption kinetics for heat pump applications. Microporous Mesoporous Mater. 2014, 193, 115-121.

33. Freni, A.; Dawoud, B.; Bonaccorsi, L.; Chmielewski, S.; Frazzica, A.; Calabrese, L.; Restuccia, G. Characterization of Zeolite-based Coatings for Adsorption Heat Pumps; Springer International Publishing: Cham, Switzerland, 2015.

34. Henninger, S.K.; Schmidt, F.P.; Henning, H.-M. Water adsorption characteristics of novel materials for heat transformation applications. Appl. Therm. Eng. 2010, 30, 1692-1702.

35. Henninger, S.K.; Jeremias, F.; Kummer, H.; Schossig, P.; Henning, H.-M. Novel sorption materials for solar heating and cooling. Energy Proced. 2012, 30, 279-288. 
36. Okamoto, K.; Teduka, M.; Nakano, T.; Kubokawa, S.; Kakiuchi, H. The development of AQSOA water vapor adsorbent and AQSOA coated heat exchanger. In Proceedings of the International Symposium on Innovative Materialsfor Processes in Energy Systems (IMPRESS 2010), Singapore, 29 November-1 December 2010; pp. 27-32.

37. Jänchen, J.; Ackermann, D.; Weiler, E.; Stach, H.; Brösicke, W. Calorimetric investigation on zeolites, $\mathrm{AlPO}_{4}$ 's and $\mathrm{CaCl}_{2}$ impregnated attapulgite for thermochemical storage of heat. Thermochim. Acta 2005, 434, 37-41.

38. Lehnert, F.; Lotze, G.; Stephani, G. Herstellung, eigenschaften und anwendung metallischer kurzfasern. Materialwiss. Werkstofftech. 1991, 22, 355-358.

39. Andersen, O.; Meinert, J.; Studnitzky, T.; Stephani, G.; Kieback, B. Highly heat conductive open-porous aluminium fibre based parts for advanced heat transfer applications. Materialwiss. Werkstofftech. 2012, 43, 328-333.

40. Andersen, O.; Studnitzky, T.; Kostmann, C. Bauteil Sowie Seine Verwendung. German Patent DE102007042494, 3 September 2007.

41. Andersen, O.; Stephani, G.; Meyer-Olbersleben, F.; Neumann, P. Properties of highly porous metal fibre components for high temperature applications. In Proceedings of the International Conference on Powder Metallurgy \& Particulate Materials, Princeton, NJ, USA, 31 May-4 June 1998; Volume 3, pp. 87-97

42. Veyhl, C.; Fiedler, T.; Andersen, O.; Meinert, J.; Bernthaler, T.; Belova, I.V.; Murch, G.E. On the thermal conductivity of sintered metallic fibre structures. Int. J. Heat Mass Transf. 2012, 55, 2440-2448.

43. Frazzica, A.; Füldner, G.; Sapienza, A.; Freni, A.; Schnabel, L. Experimental and theoretical analysis of the kinetic performance of an adsorbent coating composition for use in adsorption chillers and heat pumps. Appl. Therm. Eng. 2014, 73, 1020-1029.

44. Füldner, G. Stofftransport und Adsorptionskinetik in porösen Adsorbenskompositen für Wärmetransformationsanwendungen; Albert-Ludwigs-Universität Freiburg: Freiburg im Breisgau, Germany, 2015. (In German)

45. Kast, W. Diffusive mass transfer with superimposed frictional flow. Int. J. Heat Mass Transf. 2001, 44, 4717-4724.

46. Schnabel, L. Experimentelle und Numerische Untersuchung der Adsorptionskinetik von Wasser an Adsorbens-Metallverbundstrukturen. Ph.D. Thesis, Technische Universität Berlin, Berlin, Germany, 2009. (In German)

47. Wittstadt, U.; Jahnke, A.; Schnabel, L.; Sosnowski, M.; Schmidt, F.P.; Ziegler, F. Test facility for small-scale adsorbers. In Proceedings of the International Sorption Heat Pump Conference 2008, Seoul, Korea, 23-26 September 2008.

48. Núñez, T. Charakterisierung und Bewertung von Adsorbentien für Wärmetransformationsanwendungen; Albert-Ludwigs-Universität Freiburg: Freiburg im Breisgau, Germany, 2001. (In German)

(C) 2015 by the authors; licensee MDPI, Basel, Switzerland. This article is an open access article distributed under the terms and conditions of the Creative Commons Attribution license (http://creativecommons.org/licenses/by/4.0/). 